\title{
Sodium conservation by the small intestine in a patient with chronic ileostomy diarrhoea
}

\author{
N. D. GALlaGher, D. D. HARRISON, J. V. WYATT, AND A. P. SKYRING \\ From the A. W. Morrow Department of Gastroenterology, \\ Royal Prince Alfred Hospital, Sydney, Australia
}

Patients with established ileostomies have been shown to be predisposed to episodes of sodium depletion as a result of the excretion of large amounts of sodium in the stools (Gallagher, Harrison, and Skyring, 1962). In this earlier paper we also described three patients in whom analysis of ileostomy material revealed a decreased sodium concentration and an increased potassium concentration, at a time when they were sodium-depleted. The similarity of this response to that of other organs during sodium depletion suggested that the small intestine might contribute to the body's conservation of sodium. This paper describes the results of a study in which the magnitude of this response was measured in a patient with chronic ileostomy diarrhoea and depletion of both sodium and potassium.

\section{CASE REPORT}

The patient was admitted for the first time in 1959 at the age of 18 with a diagnosis of acute ulcerative colitis. The severity of the illness led to an emergency colectomy which was performed by $\mathrm{Mr} \mathrm{N}$. Wyndham 17 days after admission. The colon was diffusely involved by the ulcerative process but the $15 \mathrm{~cm}$ of ileum in the operative specimen was not affected. The ileostomy functioned satisfactorily in the postoperative period but intermittent vomiting developed and a barium meal examination suggested that there was an obstruction at the junction of the second and third parts of the duodenum. The vomiting settled and the patient was discharged but he returned two months later with bright red bleeding from the ileostomy.

A further haemorrhage from the ileostomy in 1960 resulted in an explanatory laparotomy. Multiple petechial haemorrhages were found in the stomach and duodenum but a bleeding point was not found in the second part of the duodenum which was the site of a peptic ulcer. Gastroenterostomy with vagotomy was performed and a biopsy was taken from the head of the pancreas. Examination of this specimen revealed the presence of chronic pancreatitis. There has been no further haemorrhage but ileostomy diarrhoea and steatorrhoea, $30 \mathrm{~g} /$ day, are now present.

The patient manages a sheep run in an area which has a hot, dry climate for the greater part of the year. Despite oral supplements of sodium, symptoms of anorexia and weakness have led to frequent admissions for treatment with sodium chloride intravenously. The present study was carried out in a metabolic ward on one of these occasions.

Investigation of the patient's fluid and electrolyte status at the time of the admission revealed a serum sodium level of $132 \mathrm{~m}$-equiv/l., serum potassium 4.5 m-equiv/l., serum bicarbonate 22 m-equiv/l., serum chloride $96 \mathrm{~m}$-equiv/l., and blood urea $36 \mathrm{mg} / 100 \mathrm{ml}$. The urine contained less than $1 \mathrm{~m}$-equiv of sodium and only $2 \mathrm{~m}$-equiv of potassium in a $24-\mathrm{hr}$ volume of $600 \mathrm{ml}$. The $p \mathrm{H}$ of the urine was 6.5 and the specific gravity was 1.010 .

The marked renal conservation of sodium and potassium indicated that the ileostomy diarrhoea was responsible for excessive losses of both of these electrolytes. In view of this finding it was decided to correct the electrolyte deficit by dietary means and at the same time to measure any changes in the excretion of sodium and potassium from the ileostomy.

MATERIALS AND METHODS The basic diet contained 95 m-equiv of sodium and 95 m-equiv of potassium. Sodium chloride supplements were provided in a salt shaker and in crushed tablets which were washed down with water. Potassium chloride was provided in gelatin capsules which were retained in the mouth for a short period before swallowing.

The diet and ileostomy material were prepared for analysis after homogenization with water which reduced their solid content to less than $10 \%$ by volume. The sodium and potassium content of aliquots of the diet, food residue, and ileostomy material were measured in a Perkin-Elmer flame spectrophotometer. Blood was taken for estimation of serum electrolytes and blood urea at five-day intervals during the 30 days of the study.

RESULTS The dietary intake and excretion of sodium, potassium, and water in the ileostomy material and in the urine are shown in Table I. The results represent the means of the values which were obtained in each five-day period. The sodium intake was increased in successive periods with the exception of the second period when it was temporarily reduced. An attempt to keep the potassium and fluid intake at a constant level was only partially successful. Dietary fat intake was maintained at $80 \mathrm{~g}$. 
T A B L E I

DAILY INTAKE AND EXCRETION OF SODIUM, POTASSIUM, AND WATER

\begin{tabular}{|c|c|c|c|c|c|c|c|c|c|}
\hline $\begin{array}{l}\text { Number of } \\
\text { Study Period }\end{array}$ & $\begin{array}{l}\text { Sodium } \\
\text { Intake } \\
\text { (m-equiv) }\end{array}$ & $\begin{array}{l}\text { Ileostomy } \\
\text { Sodium } \\
\text { (m-equiv) }\end{array}$ & $\begin{array}{l}\text { Urinary } \\
\text { Sodium } \\
\text { (m-equiv) }\end{array}$ & $\begin{array}{l}\text { Potassium } \\
\text { Intake } \\
\text { (m-equiv) }\end{array}$ & $\begin{array}{l}\text { Ileostomy } \\
\text { Potassium } \\
\text { (m-equiv) }\end{array}$ & $\begin{array}{l}\text { Urinary } \\
\text { Potassium } \\
\text { (m-equiv) }\end{array}$ & $\begin{array}{l}\text { Fluid } \\
\text { Intake } \\
(\mathrm{ml})\end{array}$ & $\begin{array}{l}\text { Ileostomy } \\
\text { Output } \\
(\mathrm{g})\end{array}$ & $\begin{array}{l}\text { Urine } \\
\text { Volume } \\
(\mathrm{ml})\end{array}$ \\
\hline 1 & 242 & 161 & 0.5 & 92 & 51 & 5 & 2,730 & 1,750 & 620 \\
\hline 2 & 168 & 108 & 1 & 102 & 50 & 18 & 2,420 & 1,370 & 760 \\
\hline 3 & 212 & 135 & 1 & 123 & 51 & 35 & 2,760 & 1,470 & 780 \\
\hline 4 & 216 & 166 & 1 & 125 & 52 & 56 & 2,140 & 1,630 & 630 \\
\hline 5 & 273 & 205 & 4 & 130 & 36 & 88 & 2,990 & 1,660 & 615 \\
\hline 6 & 306 & 204 & 29 & 123 & 14 & 102 & 2,600 & 1,460 & 670 \\
\hline
\end{tabular}

${ }^{1}$ Each period lasted for five days.

Sodium, potassium, and water excretion in ileostomy material Sodium excretion from the ileostomy fell from $161 \mathrm{~m}$-equiv/day in the first period to $108 \mathrm{~m}$-equiv/day in the second period, at the same time as the amount of sodium in the diet was reduced. However, the amount of sodium excreted from the ileostomy increased in later periods until finally 205 m-equiv of sodium was excreted in periods 5 and 6 . Potassium excretion from the ileostomy did not alter between periods 1 and 4 (50 to 52 m-equiv/day) but it fell progressively in periods 5 and 6 to 36 and $14 \mathrm{~m}$-equiv/day. The weight of ileostomy material, which ranged from 1,370 to $1,750 \mathrm{~g} /$ day, did not alter appreciably during the time of the study.

Urinary excretion of sodium, potassium, and water Less than 1 m-equiv of sodium was present per day in the urine in periods 1 to 4 . Sodium began to appear in the urine in period 5 until a maximum of 29 m-equiv/day was reached in period 6 . The potassium in the urine showed a progressive increase from $5 \mathrm{~m}$-equiv/day in period 1 to $102 \mathrm{~m}$-equiv/day in period 6 . The total potassium in the urine and ileostomy material in the latter period approximated to the amount in the diet. There was no alteration in the urine volume during the course of the study. Less than 1 1./day was collected in each of the six periods. However, the specific gravity of the urine, which was initially 1,010 , rose to 1,026 by the completion of the study.

Concentration of sodium and potassium in serum and ileostomy material The sodium concentration of the ileostomy material, which was $103 \mathrm{~m}$-equiv $/ \mathrm{kg}$ at the time of admission, fell during period 2 to $77 \mathrm{~m}$-equiv $/ \mathrm{kg}$ but it rose thereafter until concentrations were reached which were within the range found in healthy ileostomy patients (107 to 133 m-equiv/l., Gallagher et al, 1962). The serum concentration, which was initially 132 m-equiv/l. fell to a level of $128 \mathrm{~m}$-equiv/l. at the end of period 2 but rose to $143 \mathrm{~m}$-equiv/l. in period 6 . The changes in the serum sodium concentration were similar to those in ileostomy material obtained at corresponding times during the study (Fig. 1).

The potassium concentration of the ileostomy material was inversely related to the sodium concentration. The highest concentration of potassium $(41 \mathrm{~m}$-equiv $/ \mathrm{kg})$ was found in the second period, the period of temporary sodium restriction, at which time the lowest concentration of ileostomy sodium was also found. With the correction of the sodium deficit in period 6 , the potassium concentration fell to the levels of 3 to $11 \mathrm{~m}$-equiv $/ \mathrm{kg}$ which are usually found in ileostomy material (Smiddy, Gregory,
Smith, and Goligher, 1960; Gallagher et al, 1962). No relationship was found between the concentration of potassium in serum and ileostomy material.

Sodium and potassium ions in ileostomy material and the weight of the ileostomy output A linear relationship existed between the sum of the sodium and potassium

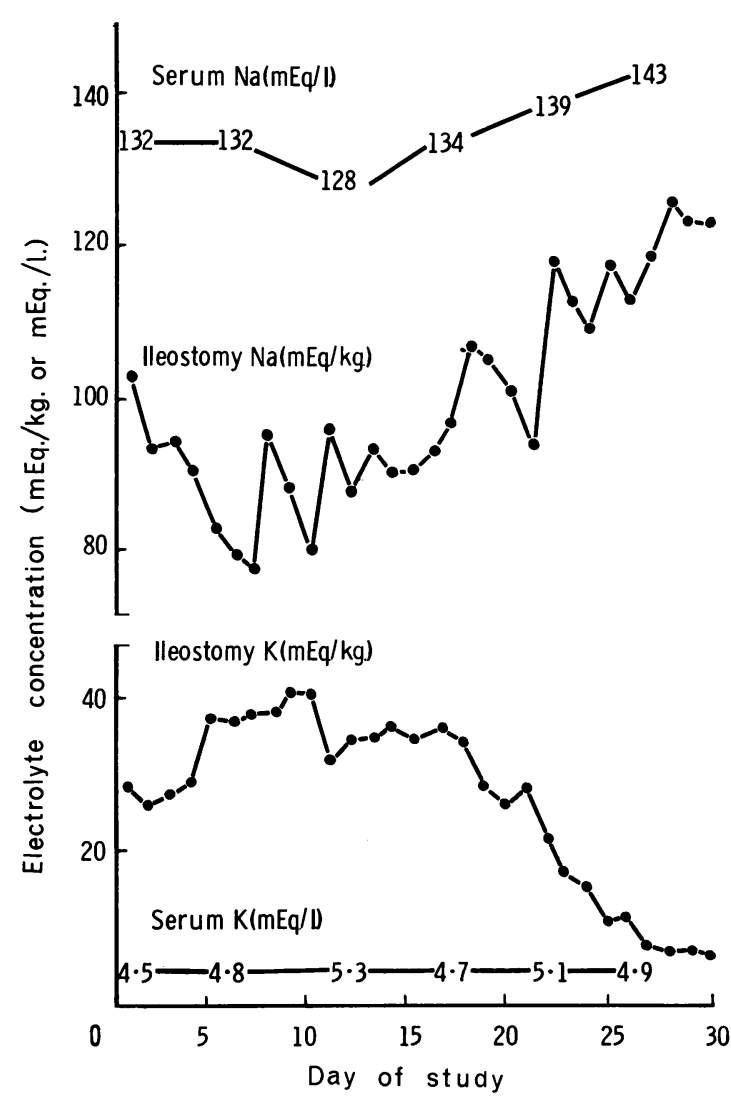

FIG. 1. Changes in serum and ileostomy electrolyte concentrations accompanying the correction of electrolyte deficiencies. 


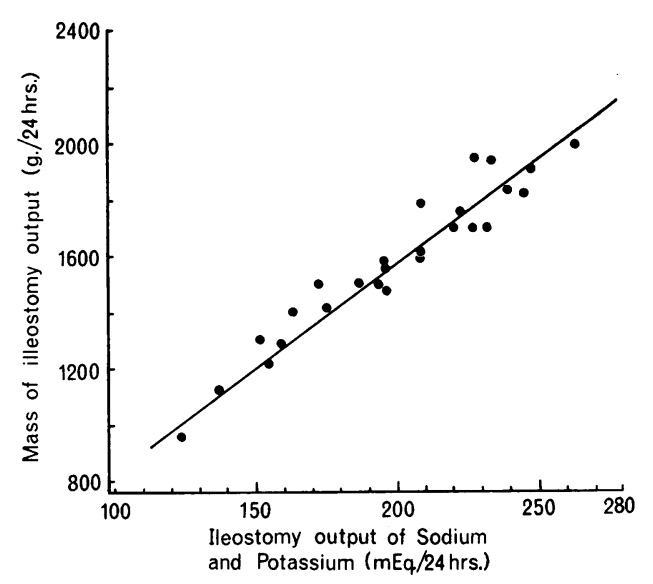

FIG. 2. Relationship between the weight of the ileostomy material and the content of sodium and potassium ions.

ions and the weight of the ileostomy material (Fig. 2). The relationship between these measurements may also be expressed in the form, sodium concentration plus potassium concentration $=127 \pm 6.3$ m-equiv $/ \mathrm{kg}$ (mean \pm 1 standard deviation). The weight of the ileostomy material was more closely related to the total content of sodium and potassium ions $(r=0.96)$ than to the amount of sodium ions alone $(r=0 \cdot 88)$.

\section{DISCUSSION}

When the study began it was found that the patient's kidneys were conserving sodium and potassium due to excessive losses of these electrolytes from the small intestine. As the study progressed it became evident that the small intestine was also conserving sodium. This occurred in each of the first four periods in which sodium did not appear in the urine and was most apparent in the second period following the temporary reduction in the dietary sodium level. Sodium conservation by the small intestine, which reached a maximum of $100 \mathrm{~m}$-equiv/day at this time, was much greater than that which was observed by Kramer (1966) who studied healthy ileostomy patients on a low sodium diet for a short period and concluded that their ability to conserve sodium was limited. This difference can be explained by the severity of the sodium depletion in our patient who gained $7 \mathrm{~kg}$ in weight during his admission.

The conclusion that the small intestine was conserving large amounts of sodium may be questioned because the dietary intake of sodium was not kept at constant level. Hence an alternative explanation for the variation in ileostomy sodium excretion is that it followed changes in the sodium intake and was therefore independent of the state of the body sodium stores. However, the observation that changes in the serum sodium concentration were closely linked with those in ileostomy material makes it unlikely that the small intestine was acting as a mere conduit. Moreover, at no time was the concentration of sodium in the homogenized ileostomy material greater than $132 \mathrm{~m}$-equiv/ $\mathrm{kg}$ whereas sodium concentrations of 200 to 400 m-equiv/l. have been reported in ileostomy material containing unabsorbed dietary sodium (Crawford and Brooke, 1958).

In view of the importance of socium in determining the volume of the various extracellular fluid compartments it is of interest that the output of fluid from the ileostomy did not change when the small intestine was conserving sodium. It was found that the weight of the ileostomy material was more closely related to the total quantity of sodium and potassium ions than to the content of sodium ions alone. Hence it appears that the increased intestinal excretion of potassium when the patient was sodiumdepleted offset the effects of a reduction in sodium excretion. The ability of the small intestine to excrete potassium in exchange for sodium was reflected in the electrolyte concentrations of ileostomy material obtained at different times during the study. The lowest concentrations of sodium (minimal value, $77 \mathrm{~m}$-equiv $/ \mathrm{kg}$ ) and the highest values of potassium (maximum, $41 \mathrm{~m}$-equiv $/ \mathbf{k g}$ ) were found when the patient was most severely depleted of sodium, whereas the sodium concentration of $123 \mathrm{~m}$-equiv $/ \mathrm{kg}$ and the potassium concentration of $7 \mathrm{~m}$-equiv/ $\mathrm{kg}$ had returned to within the normal range by the completion of the study.

It has previously been shown that the administration of 9- $a$ fluorohydrocortisone to ileostomy patients results in a reduction in the ileostomy sodium-potassium ratio (Goulston, Harrison, and Skyring, 1963). A similar, presumably hormonally mediated response was present in the patient in this study when he was sodium-depleted. In contrast to the results in the large bowel (Levitan and Ingelfinger, 1965) attempts to demonstrate an effect of the naturally occurring, salt-retaining hormone, aldosterone, on human small intestine have been unsuccessful. However, Clarke, Hill, and Macbeth (1967) have now shown that the administration of spironolactone, an aldosterone antagonist, to a sodium-depleted ileostomy patient resulted in an increase in the intestinal excretion of sodium. We have also obtained evidence for an effect of aldosterone on the excretion of sodium by the small intestine in similar studies (unpublished observations). Studies of this type, which have been shortlived because of the rapidity with which symptoms of acute sodium depletion develop, have not provided any indication of an effect of aldosterone on 
intestinal potassium loss. However, in view of the nature of the changes in the excretion of electrolytes in the present study, it is probable that aldosterone will be shown to influence the small intestinal excretion of both sodium and potassium.

The major problem in the management of this patient has been to prevent the development of sodium depletion. No difficulty has been experienced in maintaining him in a state of positive potassium balance in the time immediately after his leaving hospital because potassium losses from either the kidneys or from the ileostomy have been no greater than those which are found in healthy individuals. Hence it is assumed that when the patient begins to conserve sodium, in response to an inadequate dietary intake, intestinal potassium excretion is increased, thereby playing a large part in the development of his potassium depletion.

It is possible that the information gained in this study will prove to have a wider application since we have observed, in confirmation of the studies of Lubran and McAllen (1951) and of Smiddy et al (1960), that the stools of patients with ulcerative colitis may contain sodium and potassium in concentrationsidentical with those obtained from healthy ileostomy patients. The similarity between these results suggests that in a number of patients with ulcerative colitis small bowel fluid is transported through the large bowel without undergoing marked changes in its electrolyte composition. Thus it can be postulated that when sodium depletion develops in these patients potassium depletion will appear in a manner similar to that described in the ileostomy patient in this study.

\section{SUMMARY}

This paper describes an investigation of the extent of intestinal sodium conservation in a patient with chronic ileostomy diarrhoea who was admitted at a time when he was depleted of both sodium and potassium. The amounts of sodium and potassium which were excreted in the stools and urine were measured on each of 30 days during which time the electrolyte disturbances were corrected by dietary means. Daily losses of ileostomy sodium were shown to be greatest (205 m-equiv) when electrolyte balance was restored, but as little as 108 m-equiv was excreted daily during sodium depletion. The daily excretion of potassium from the ileostomy, which reached a maximum of $52 \mathrm{~m}$-equiv when the patient was sodium depleted, fell to 14 m-equiv by the completion of the study. The weight of the ileostomy output, which was directly related to the amount of sodium and potassium ions, did not alter during the course of the study. It is concluded that the small intestine of the patient in this study played a significant part in sodium homeostasis but that this occurred at the expense of potassium which was then found in the stools in increased amounts.

We wish to acknowledge the assistance of the Bushell Trust and the Post-Graduate Medical Foundation of the University of Sydney.

Requests for reprints should be addressed to: Dr N. D. Gallagher, Department of Medicine, University of Sydney, Sydney, N.S.W. 2006, Australia.

\section{REFERENCES}

Clarke, A. M., Hill, G. L., and Macbeth, W. A. A. G. (1967). Intestinal adaptation to salt depletion in a patient with an ileostomy. Gastroenterology, 53, 444-449.

Crawford, N., and Brooke, B. N. (1958). Ileostomy chemistry. Lancet, 1,586 .

Gallagher, N. D., Harrison, D. D., and Skyring, A. P. (1962). Fluid and electrolyte disturbances in patients with long-established ileostomies. Gut, 3, 219-223.

Goulston, K., Harrison, D. D., and Skyring, A. P. (1963). Effect of mineralocorticoids on the sodium/potassium ratio of human ileostomy fluid. Lancet, 2, 541-542.

Kramer, P. (1966). The effect of varying sodium loads on the ileal excreta of human ileostomized subjects. J. clin. Invest., 45, 1710-1718.

Levitan, R., and Ingelfinger, F. J. (1965). Effect of d-aldosterone on salt and water absorption from the intact human colon. Ibid., 44, 801-808.

Lubran, M., and McAllen, P. M. (1951). Potassium deficiency in ulcerative colitis. Quart. J. Med., 20, 221-232.

Smiddy, F. G., Gregory, S. D., Smith, I. B., and Goligher, J. C. (1960). Faecal loss of fluid, electrolytes, and nitrogen in colitis before and after ileostomy. Lancet, 1, 14-19. 